\title{
Preface: Competing Chinese Conceptions of the PRC's Possible Futures
}

A MARCH 24, 20 I 4, GOOGLE SEARCH uncovered nearly I3 million Internet pages addressing some aspect of "the rise of China." In the twenty years since William H. Overholt first published his prophetic book with that title, ${ }^{1}$ the world has become enthralled with the idea of an increasingly powerful People's Republic growing economically at 9 percent a year, endlessly into the future. What would the implications of such a world-historical development be for the structure of international relations? Would Anglo-American civilization conclusively lose its (already fading) global preeminence? How might a power transition be managed peacefully, given the awesomely destructive weapons that both China and the United States possess? ${ }^{2}$ Would the transition be less problematic if economic reform and opening lead China onto a path of democratization? As recently as the I990s, many observers considered that it would be impossible for the PRC to rise successfully and yet remain authoritarian. Even today, quite a few political scientists continue to insist that democratization is, if not inevitable, at least strongly likely, given China's transformative economic changes and the associated social pluralization. ${ }^{3}$ If democratization is inevitable or at least highly likely, why should anyone be concerned that a successful Chinese rise might lead to the power transition becoming acrimonious or even violent? Or, from an entirely different angle, is it not possible that democratization would be more likely to occur in the event China's massively complex mix of economic, environmental, and demographic challenges-unprecedented for any country in modern history-were to cause the rise to stall?

All of these questions (and more) are at the forefront of contemporary debate among political and other social scientists, international relations scholars, policy analysts and government officials, journalists, business people, NGO professionals, and everyday concerned citizens. China's stunning economic successes invite intense and widespread rumination 
about how the PRC and the world will together change if the PRC's rise succeeds-or, in other words, if China realizes "the China Dream" concept that $\mathrm{Xi}$ Jinping co-opted from left-leaning nationalist groups (but then reformulated) on his ascent to power in November 20I2. Xi uses "the China Dream" to describe-albeit vaguely-the thoroughly desirable end state to which China's development is inevitably leading, with success expected about $2050 .{ }^{4} \mathrm{Xi}$ is far from alone in issuing confident predictions concerning China's future, although his motivations are distinctive. Any casual survey of the global media and blogosphere creates the impression that nearly everyone is taking a stab at it, and certainly a large plurality of the world's leading social scientists and public intellectuals are doing so. Some observers express their predictions with more conviction than others; often, the most confident "predictioneers," to use Bruce Bueno de Mesquita's term, are social scientists. ${ }^{5}$ Although strongly self-confident predictions can be useful for helping to focus thought, stimulate debate, and shape research agendas, they should always be treated with caution and skepticism. The starting point of this book is the simple observation-elaborated in Chapter I-that no matter how scientific a predictioneer's model may appear to be, the future can never be known, because (I) there are too many factors in play that will affect it, and (2) even if the factors could be mapped and measured, human agency ("free will" - critical though circumscribed), along with chance events, will always intervene to make predicting with reliable accuracy impossible.

On the other hand, it would be foolish and irresponsible to abandon all efforts at thinking systematically about what the future may bringor, in our case, which of several plausible, but competing, developmental trajectories China might take in the specific subarenas of the economy, politics, public culture, and foreign policy. As elaborated in Chapter I, thinking through different possible trajectories and their varying implications can be useful for formulating policy (for government, business, or any other affected entity) in the present-not only in the negative sense of preparing for the worst but also to spot those developments that seem to provide opportunities for encouraging positive change. Analyzing current trends for insight into which of the competing trajectories seems the 
most probable is, obviously, not the same as analyzing the future itself, which, by definition, is impossible-because nothing in the future has happened yet.

To date, very few of the observers struggling to get a handle on China's developmental course have devoted their energies to analyzing systematically the varying images of the future circulating within China itself; that is, the discussions and debates concerning China's possible trajectories that the PRC's huge cadre of smart, well-informed, hard-working, and public-minded policy analysts (whether in academia, think tanks, government, or business) engage in every day. In any country, images of the future-or competing conceptualizations of the national trajectory as manifest in economics, politics, culture, foreign policy, and other issueareas-help to shape real-world policy making (and private sector decision making) in the present and consequently the trajectory itself. Especially in a still superauthoritarian country like China, images articulated by elites (broadly conceived) are likely to be highly valuable-even though so far underexploited-windows on what the future might hold. Researchers can study these images in an effort to understand different possible trajectories even if the analysts who circulate them are acting within the boundaries of broad Party guidelines. This is because of the near-certainty that the authoritarian power center will exert the dominant influence over which of several different paths China ends up taking. So whether intellectual (or other) elites affect the leaders' thinking, or, in contrast, the leaders shape the elites' research and assessment agendas, either way, the images elites circulate can serve as a mirror on the policy choices the power center is most likely to face.

Elite images are obviously not the only important factor shaping a country's developmental trajectory. Material factors related to geography, demography, the economy, and the environment are also critically important, along with exogenous factors originating in foreign countries or global society. But this book assumes that what high-profile figures within the Chinese establishment think and say about their country's developmental trajectory, along with their recommendations for how the trajectory should be altered to achieve a more desirable future, can be 
used as potent indicators providing insight into what the future may become. It should make a significant difference that, as explained in Chapter 2, the overwhelming majority of China's economists vigorously criticize current economic arrangements and demand liberal alternatives; while, as elaborated in Chapters 5 and 6, the country's foreign policy specialists are mostly tough-minded realists convinced of the absolute rightness of China's international claims and the inevitability of the national rise succeeding. It would equally make a difference (in the opposite direction) if a majority of Chinese political scientists were calling for-and saying they expected-democratization, while the majority of international relations specialists were cautioning that because China's territorial and other contested claims are "constructed" rather than absolute, China must compromise with neighboring countries and Taiwan for the sake of global stability. To repeat, this is not to argue that elite images invariably shape policy, or that Chinese intellectuals determine the CCP's policy agendas. Under certain circumstances this surely does happen-Party-state leaders constantly solicit the views of policy-oriented intellectuals-but ultimately the CCP sets the boundaries and shapes the agendas of discourse. ${ }^{6}$ The critical point is that even when Chinese analysts are simply reflecting the demands of the Party Center in the images of the future they create and circulate, studying these images-how they reflect what is expected and what (possibly in contrast) would be normatively desirable-can be highly useful in trying to assess what the trajectory is likely to become, precisely because the elites are operating inside parameters imposed by the (still) awesomely powerful Party-state.

Each of Chapters 2 through 6 addresses Chinese thinking about a particular issue-area and how current trends either are or are not, in the minds of Chinese elites, leading to a desirable future. Chapter 2 examines the economy and demography. Chapter 3 focuses on the structure and dynamics of the political system. Chapter 4 turns to communication and culture construction, or the new "network society" made possible by rapid media and telecommunications development. Chapters 5 and 6 focus on different dimensions of China's trajectory in international relations. The concluding Chapter 7 outlines various possible scenarios for China's future (the next decade or so), approaching the task by tying together the core 
findings of each of Chapters 2 through 6 and briefly addressing more recent developments such as the pledges made concerning economic reform at the CCP's “Third Plenum” in November 2013 and the near-simultaneous declaration of an "Air Defense Identification Zone" over most of the East China Sea. For this is the central tension in the Chinese images uncovered in this research: Some elites, especially economists, view China's rise as perched precariously on the edge of a devastating crisis, which would center on a sharp slowdown in economic growth even if complex, risky, and divisive reforms are implemented; whereas others, especially international relations specialists (though not all of them), express a heedless hubris that nothing could stop China's rise; therefore, the time has come to assert China's CCP-defined national interests much more boldly and vigorously than at any point since at least the mid-r990s. These two groups do not even seem to talk to each other, though the economists are far more aware of (and worried about) the brashness of the IR specialists than the other way around. Through systematic reading and interviews, one arrives at the inescapable conclusion that most IR scholars do not even bother to concern themselves with what the economists are writing, even though the economists' warnings of inevitable trouble strike at the core of the nationalist IR specialists' boundless optimism, which fuels or reinforces risky policy choices. This central tension and its implications will become evident in the chapters to follow.

SOURCES AND METHODS

The book is based primarily on analysis of Chinese-language neibu (internal-circulation only) and open-source journal articles, most with a strong policy focus; books and book chapters published by establishment PRC presses; some Party newspaper articles; and, to reinforce points of fact, occasional reports from foreign (especially Western) news outlets. Neibu journals can be particularly valuable to researchers because the restrictions on their circulation combined with their policy focus work together to ensure that contributing authors (usually academics-from both universities and think tanks-but also Party and government officials and the occasional businessperson) speak more candidly (sometimes surprisingly so) than analysts publishing in open journals or books. Neibu 
journals vary in the number-and type-of PRC Party-state officials technically permitted to read them, although circulation figures and the specific restrictions are never detailed in the journal issues themselves. None of the neibu journals to which a foreign scholar can, through various avenues, secure access is likely to be of the "top secret" variety. The subjects that available journals cover are indeed sensitive but not usually the most sensitive issues facing China; for example, only rarely does one find articles frankly addressing the resistance movements in Xinjiang and Tibet, or offering forthright assessments of corruption among higher-ranked (and never the highest-ranked) leaders. But contributors to neibu journals often do inadvertently reveal fascinating details about the problems facing China. From a meta-analytical perspective, they also make obvious that Chinese policy is always being vigorously, sometimes even fiercely, debated. The image of a monolithic China in which everyone thinks alike-the image that all Chinese are unreasonable nationalists, for example, or that all support without qualification breakneck, investment-led, economic growth-is manifestly false. China today is a kaleidoscopically plural society-although still, to be sure, always subject to the Leninist state's discipline should the leaders decide, for whatever reason, to crack down, either on a whole category of activity/discourse or on a particular person who has irritated a local tyrant. ${ }^{7}$

The neibu journals serve as venues for the most cogent analyses of China's problems and the most contentious debates, but even mainstream academic journals and books are far livelier and more forthright today than even a decade ago, with a few notable exceptions (for example, probably no open journal in the PRC's history was more lively and forthright than the iconoclastic and unpredictable Strategy and Management, banned by Hu Jintao in August 2004). Consequently, I also make extensive use in this book of mainstream Chinese academic journals and books, with most of the materials I use published between 2006 and 20I3. Although it would have been impossible (and even undesirable, as explained in the following discussion) to survey such sources strictly at random-partly because foreign scholars inevitably have only limited access to PRC books and journals, especially neibu journals-I constantly kept in mind the possibility that my sample could become systematically biased. To avoid 
this pitfall, whenever I came to a point in my reading where I felt that all or most of the voices were trending in one direction, I would selfconsciously go back to the journals to confirm that I had not overlooked dissenting voices. It was important to make certain that the "trending" I was detecting accurately reflected the broader universe of publications concerning the issue-area. My core criterion for including an article, book, or book chapter in the sample was simply that the author of the text had to be systematically addressing some aspect of China's trajectory, with an eye on the policy implications for shaping what the author considered to be a more desirable future.

A second criterion was that the citations had to be distinctive and original in the context of all the citations that might have been included in the sample. Within the universe of published policy-and future-oriented Chinese publications to which a foreign scholar might have access, only a small percentage will be novel, distinctive, original, or insightful, whereas countless others simply echo the findings of other scholars or, more often, the propaganda line of the Party Center as expressed in slogans and codeterminology. For this book, I wanted to analyze and discuss only writings that appeared genuinely to contribute to debates, not by "piling on" through copying-and-pasting verbiage from other people's publicationsor the Party-state's-but instead by offering fresh perspectives, whether critical of the state or supportive, in a spirit in which "CCP talk"-so full of vacuous slogans and arcane code-terminology-is largely ignored except in a polite few opening lines.

To locate the high-value-added citations required first wading through giant stacks of other publications, most of which ended up being rejected because they were either obviously derivative or else purely propagandistic. So, for example, I decided to exclude from the sample all articles and chapters devoted simply to echoing the pet political slogans of the Party General Secretary, without offering any substantive analysis of the slogans or their implications. I certainly had no objection to including citations in which, for example, the author would seriously analyze and ultimately embrace Hu Jintao's twin concepts of "harmonious society" and "harmonious world." But to make it into the sample, the author had to probe the concepts, explain their origins, elaborate on their significance, 
forthrightly address their weaknesses, and/or candidly assess prospects for their successful implementation-somehow, in other words, add value, advance understanding, or offer an alternative interpretation. To be included, writers did not necessarily have to oppose the Party leadership or reject the leaders' slogans; they simply had to demonstrate an analytical, critical cast of mind in receiving and reflecting on the Party line. The goal of the research was to map the range of debates on the trajectory, not to insist on uncovering a mythical, unified "Chinese state of consciousness," whether supportive or subversive. In the end, I did find dominant tendencies in the discourse for each of the separate issue areas. But with the notable exception of the economics discourse, in which a high degree of (liberal) unity prevails, the differing points of view on display in each chapter are in some respects even more revealing than the underlying commonalities and shared assumptions.

A second kind of often-seen but low-value-added article or book chapter may not be purely derivative or propagandistic but will be "light" or even "cute" in tone, not taking the country's challenges seriously. The authors of such essays will invariably raise a few problematic issues but then spend most of their time cheerily insisting (without confronting any discomforting evidence) that "everything will work out in the end thanks to the Communist Party's wise leadership." This special genre of bland, "happy ending" pieces does, in a sense, showcase writers predicting the future, but not in a way that inspires confidence the writers have given the matter serious thought. The thoughtlessly happy pieces are not the sort of articles one would want in a sample of Chinese writing on the future-and therein lies a key reason that sampling at random would be problematic for more than just reasons of access. Because articles and books of this lighthearted and "fluffy" genre are overwhelmingly voluminous, joining the pure propaganda and endless copying-and-pasting of others' works in clogging the bookshelves and diluting the contents of otherwise highquality journals, any random sample would have captured far too many such analytically useless pieces, whose authors seem to be motivated more by a determination not to inquire into China's trajectory with intellectual rigor, but instead to signal ingratiatingly to the Party that "I am with the 
program and not a troublemaker; no matter what those doom-and-gloom naysayers may conjure up next, I will always serve you loyally." Under Mao, this kind of fear-driven and/or opportunistic obsequious behavior was termed biaotai, or "expressing one's attitude" — and the attitude always had to be positive and enthusiastic, no matter what the person behind the pen might actually think. As subsequent chapters make clear, the works of numerous optimists and regime supporters did meet the sample criteria and were consequently included. What distinguished the writings of these supportive and optimistic analysts from those who wrote in the platitudinous happy-talk genre was that in the course of arriving at their optimistic conclusions, the serious analysts who were adding value to the debates forthrightly engaged at least some of the points being made by the skeptics and the pessimists.

Also requiring active exclusion from the sample was the omnipresent Party propaganda issued by the leaders themselves or by their official mouthpieces - in a manner suggesting that even they had other things on their mind when they were delivering the speech or composing the article in question. A carefully crafted, meticulously detailed policy statement could certainly be included but not something like the paintby-Party-numbers speech Hu Jintao delivered to a CCP conclave in July 2007. This speech begins with $\mathrm{Hu}$ announcing: “The Communist Party of China (CPC) takes Marxism-Leninism, Mao Zedong Thought, Deng Xiaoping Theory and the important thought of Three Represents as its guide to action and theoretical basis [for policy] ..." ${ }^{\prime}$ To be sure, speeches like this should not be dismissed as politically meaningless; clearly, they must serve some important political purpose, probably of a ritualistic nature. But such speech and articles do not serve the purpose of this book, which is to map the range, in multiple issue-areas, of genuinely believedin Chinese images of the future. Essays serving this purpose-meeting the needs of the sample-take the iron-hard reality of Party domination as a fact and then proceed to explore what this and other dimensions of reality as the authors perceive it imply for desired or likely futures. In contrast, the biaotai genre and the constantly echoing ritualistic Party propaganda must actively be excluded from the sample so that we can 
focus our inevitably limited analytical attention on the exciting, incisive, creative, and weighty debates that are flourishing in the Chinese policymaking community.

The methodological necessity, in other words, was to separate-painstakingly and with constant attention to the possibility of inadvertently introducing systematic bias-signal from noise. Sampling purely at random would have been much easier and taken far less time but in this case would have been irresponsible and lazy, an abandonment of sound methodological principles-because it would have resulted in a book devoted primarily to the analysis of noise: pointless from start to finish.

An additional problem regarding construction of the sample was the question of what to do about people "everyone knows" are influential in China, and consequently famous; or, conversely, are famous, and therefore obviously influential. I made a decision to reject any effort to predetermine-inevitably by "dead reckoning" (that is, "guessing")-who the famous or influential analysts and commentators are, then solely concentrate on their books and articles. Trying to construct a sample in that way would have been "too clever by half" insofar as it would almost certainly have introduced all manner of hidden distortions into the sample because how a person becomes famous in China-and how I then come to discover who the famous people are-are both opaque and mysterious processes very likely to be tainted by hidden biases.

At the same time, I decided that it would equally be mistaken to exclude well-known writers automatically, under the (surely false) assumption that they are all vacuous products of hype. Rejecting famous commentators simply because they are famous would have introduced an entirely different set of equally distortive biases. Well-known writers were included just so long as they met the core criteria of publishing substantive, debate-advancing articles, books, or book chapters on the subject of the trajectory in the types of outlets sampled within the time period specified.

Finally, I chose not to examine blogs, microblogs, or other popular publications. I do not deny the potential importance of such materials in shaping China's trajectory or in reflecting how the CCP intends for the trajectory to be shaped. The potential importance of Internet discourse is 
one reason I devote all of Chapter 4 to examining Chinese debates over what the ongoing communications revolutions mean for a polity that is still Leninist in structure. I posit the problématique as being China's transformation into a "network society," the powerful concept developed by sociologist Manuel Castells in the I990s. Gustavo Cardoso, the coeditor with Castells of a 2005 volume on the subject, defines the revolutionarybut still too-early-to-fathom-implications of the network society's global advent in terms that suggest profound changes may be on the horizon for the PRC’s Leninist political structure:

Perhaps what we are witnessing [worldwide, including in China] is not the disintegration and fractioning of society, but the reconstruction of social institutions and, indeed, of the structure of society itself, proceeding from autonomous projects carried out by society's [individual and group] members . . . In this perspective, the autonomization of individuals and groups is followed by their attempt to reconstruct meaning in a new social structure on the basis their selfdefined projects. By supplying the technological resources for the socialization of the projects of each individual in a network of similar subjects, the Internet, together with the mass media, becomes a powerful social reconstruction tool. ${ }^{9}$

The advent and deepening of the network society imply that within a decade or so it may well become imperative to study images of the future circulating exclusively through the Internet, in addition to images published in outlets the CCP ultimately controls. But, for now, it seems reasonable to focus on Party and Party-supervised publications, given that the CCP continues to maintain its monopoly on legitimate political power while vigorously policing media and Internet content, trying to steer the content in nonpolitical, or even frivolous, directions-except insofar as the network is useful as an administrative tool. ${ }^{10}$ Were the CCP to lose substantially more control over the network and broader information flows - or decide to abandon its efforts to control - then clearly, Internet content initiated by private citizens would become far more important to monitor and analyze.

In addition to studying written works, I conducted thirty-five formal interviews at universities and think tanks in Beijing and Shanghai in 20I0, 
2OII, and 20I2. (All interview subjects were promised anonymity, but one person preferred that I cite him by name.) Overrelying on interviews would be problematic methodologically, partly because only scholars predisposed to being friendly with foreigners will sit for them. But interviews can be exceptionally helpful for clarifying points made in books and articles and exploring potential new lines of thinking.

There are many people I would like to thank for helping to make this book possible. Let me start with the ever-effervescent and witty Professor Stanley Rosen, to whom this book is dedicated. Although I've had the pleasure during my years at USC of working with numerous colleagues who are highly accomplished and erudite, yet also friendly and down-toearth, Stan occupies a category all his own, as a truly good guy: friendly to everyone, invariably supportive of younger faculty and students, and often hysterically funny (the life, inevitably, of any USC party), while yet maintaining his status as a keen and deeply insightful observer of China and the profession of studying China. I can't imagine how substantially less rewarding my sixteen years at USC would have been if Stan had not already been firmly ensconced here as the senior Chinese politics specialist by the time I arrived. It helps that Stan is from Brooklyn, as many of my family members are, and that he is a big fan of sports and jazz music. I could not even begin to quantify the many valuable things I have learned from Stan over the years, to say nothing of the voluminous entertaining trivia he has poured into my mind. Stan is not responsible for the content of this book, of course, and he may well disagree with some of its conclusions. But he has played a central role in creating and maintaining the supportive climate in which a book like this-which requires years of patient work-can come to fruition.

Clay Dube is another special person I want to thank because of the critical role he has played in helping to turn USC into an exceptionally exciting place for studying China. Deploying his formidable administrative skills, his talent from bringing diverse people together, his own extensive knowledge of China, and his disarming friendliness and gift for garrulous gab, Clay has done a masterful job in building the USC U.S.-China Institute since assuming the leading role in that challenging task in 2006. One highly enriching result among many is that Clay 
has arranged for a continuous parade of outstanding outside speakers to come and visit USC, year after year: journalists, scholars, government officials, businesspeople, and many others, from countries throughout the world, including, of course, China itself. Without a doubt, my being able to participate in the numerous high-quality events Clay has organized has indirectly helped enriched this book. Institution building is a rare talent; we have been fortunate at USC to have Clay in place doing that selflessly every day.

Let me also thank the audiences before which I have presented various parts of this work in progress over the past few years, including at the annual meetings of the Association for Asian Studies and the International Studies Association; the City University of Hong Kong in July 20I0; Taiwan's Institute for National Policy Research in December 20IO; Renmin University of China in May 20I I; Georgia State University's Confucius Institute in April 20I2; the Thai Royal Naval Academy in August 20I3; Southern Methodist University's conference on “Asia's Contested Waters" in September 20I3; and, in between, presentations not only at USC's U.S.-China Institute, but also its Center for International Studies and Korean Studies Institute. I also owe a huge debt of gratitude to the Chinese University of Hong Kong's Universities Service Centre, four leading PRC universities in Beijing and Shanghai that I have decided not to name, and two PRC think tanks that I have also decided not to name-as well as the kind individuals who helped arrange my visits to those leading institutions of contemporary China studies.

USC's Dornsife College, the USC U.S.-China Institute, the School of International Relations (my home department), and the School's Center for International Studies all provided generous and timely grants to help fund my research trips to China, including Hong Kong.

Two anonymous manuscript reviewers both went far beyond the call of duty in offering constructively critical and penetratingly thoughtful suggestions for how I could improve the manuscript. All authors say their reviewers worked especially hard; I can assure you that mine truly did. Consequently, I approached revisions feeling a strong sense of obligation to these generous and insightful scholars. With all the effort they put in, I certainly did not intend to let them down. The same holds true 
for Michelle Lipinski, the Stanford University Press Acquisitions Editor who, from the very first day I submitted the manuscript, has been exceptionally enthusiastic and supportive. When people like Michelle go out of their way to express confidence and high aspirations for a book, I not only feel gratitude but also an enhanced motivation to make the book as strong as possible. I would not want to disappoint either Michelle or the anonymous reviewers, nor give them any grounds for thinking their confidence was misplaced.

And the same also holds for Margaret Pinette, whose meticulous and careful copy editing — striking just the right balance-was far more important in enhancing the book's overall impression of coherence than most readers will be aware. I think of Margaret, Michelle, and the two anonymous reviewers-along with the many other professionals in the Stanford University Press network, most of whom I don't even know, but who worked, and continue to work, on various aspects of the book behind the scenes-as all part of a team, a team of which I am very proud to be a member. 


$$
\text { C H I N A' S F U T UR E S }
$$


